\title{
Rehabilitative Outcomes after Hip Fracture in a Special Care Unit for Persons with Dementia and Behavioral and Psychotic Symptoms*
}

\author{
Mauro Colombo $^{1,2}$, Silvia Vitali' ${ }^{2,3}$, Chiara Cutaia ${ }^{2,3}$, Eleonora Marelli, ${ }^{1,2}$, Antonio Guaita ${ }^{2}$ \\ ${ }^{1}$ Geriatric Rehabilitation Unit/Intermediate Care, Geriatric Institute "Camillo Golgi", Agency for Services to \\ Persons (ASP) Golgi Redaelli, Abbiategrasso, Italy \\ ${ }^{2}$ Golgi Cenci Foundation, Abbiategrasso, Italy \\ ${ }^{3}$ Special Care Unit for Persons with Dementia/Intermediate Care, Geriatric Institute "Camillo Golgi", Agency for \\ Services to Persons (ASP) Golgi Redaelli, Abbiategrasso, Italy \\ Email: m.colombo@golgiredaelli.it, s.vitali@golgiredaelli.it, c.cutaia@golgiredaelli.it, e.marelli@golgiredaelli.it, \\ a.guaita@golgicenci.it
}

Received 10 August 2015; accepted 20 September 2015; published 24 September 2015

Copyright (C) 2015 by authors and Scientific Research Publishing Inc.

This work is licensed under the Creative Commons Attribution International License (CC BY).

http://creativecommons.org/licenses/by/4.0/

(c) (i) Open Access

\begin{abstract}
Aim: Hip fracture implies severe problems to older people; special concerns regard persons with dementia, due either to cognitive impairment, or to behavioral and psychic symptoms. This study illustrates rehabilitative outcomes of these patients discharged by a special care unit ruled by "GentleCare" principles. Method: 54 patients [89\% females, aged 82.3 years (range 66 - 94)] followed a post-surgery rehabilitative program carried out by a physiotherapist and an occupational therapist, supported by a psychologist. The multidimensional assessment consisted of cognition evaluation (Mini Mental State Examination, Clinical Dementia Rating, Global Deterioration Scale), functional evaluation (Barthel Index, Tinetti Gait and Balance, Bedford Alzheimer Nursing Severity scale), behavioral evaluation (UCLA Neuropsychiatric Inventory) and comorbidity evaluation (Cumulative Illness Rating Scale). Results: All parameters improved, including the 5 most frequent behavioral and psychic symptoms that usually preclude admission in ordinary rehabilitation units. 24\% of improvement in Barthel Index total score was explained by agitation and apathy at discharge, in a multiple linear regression model: better functional levels corresponded to smoother behavioral problems. Most patients improved; $70.5 \%$ of them were discharged to home. Conclusion: A prosthetic approach enables valuable results in the rehabilitation of severely demented patients with hip fracture also in presence of behavioral symptoms.
\end{abstract}

*Hip fracture rehabilitation in a special care unit for demented patients.

How to cite this paper: Colombo, M., Vitali, S., Cutaia, C., Marelli, E. and Guaita, A. (2015) Rehabilitative Outcomes after Hip Fracture in a Special Care Unit for Persons with Dementia and Behavioral and Psychotic Symptoms. Health, 7, 11751182. http://dx.doi.org/10.4236/health.2015.79132 


\title{
Keywords
}

\author{
Hip Fracture, Rehabilitation, Special Care Unit for Dementia, Gentle Care, Behavioral and Psychotic \\ Symptoms of Dementia
}

\section{Introduction}

Hip fracture impacts severely either on quality of life [1] or on objective measures of daily living. The majority of older people with hip fracture do not return to pre-fracture functional status 1 year after surgery [2]. The natural recovery curve smoothes to the end after 6 months. 12 months after hip fracture, approximately 50\% of patients are not able to walk across a small room independently. New dependency in functional activities of daily living after fractures persists throughout 1 year for many patients, $20 \%$ of them needing help wearing on pants, $50 \%$ needing assistance to walk, and $90 \%$ being dependent in climbing stairs [3]. In Italy—one of the countries with the top life expectancies, the burden of hip fractures is extremely high. The incidence of hip fractures in elderly increased by $12.9 \%$ between 2001 and 2005 (more than 80,000 in 2002 for subjects aged >65 years). In 2005, the hospital costs across the national health care system associated with hip fragility fractures in the elderly were comparable to those of stroke (both hemorrhagic and ischemic) occurring in the whole Italian adult population, and higher than those due to acute myocardial infarction and to transient ischemic attacks. More, rehabilitation costs of hip fractures were comparable to those of acute myocardial infarctions (about 530 million Euros in 2005). The costs for 1 month of post-operative rehabilitation accounted for 412 million Euros [4].

Cognitive impairment correlated with limited functional gains and a poor rehabilitation outcome in elderly patients [5]-[7]. Even among one hundred and forty-two patients with proximal hip fracture having Mini Mental Status Examination within normal range (>23/30), basic daily living and motor scores at discharge were lower according to Clock Drawing Test lower performance [8].

Cognitive impairment has been viewed as a hindrance to geriatric rehabilitation, or a restrain from being included in outcome studies [9].

Yet other studies have shown that cognitive impairment may not interfere with an effective rehabilitation of such patients, so that they may exhibit functional gains and re-enter community-living situations [10]-[13]. Hip fracture with mild or moderate dementia can often return to the community if they are provided with active geriatric rehabilitation [14]. In a specific study, after examining a relatively large sample of elderly patients after surgery for hip fracture, impaired cognitive status at admission lowered the rehabilitative outcome and was strongly and directly associated with relative functional gain, whereas absolute motor gain appeared to be independent of cognitive status. In a multiple regression analysis, cognitive performance affected the number of rehabilitative procedures after hip fracture, computed as the ratio between the sum of rehabilitative procedures and the length of hospital stay. These findings may support the implementation of comprehensive rehabilitation for selected cognitively impaired elderly hip fracture patients. These patients might need more flexible schedules and schemes, with shorter repeated issues, in quiet dedicated settings [15]. Such issue may become even more stringent in case of presence of behavioral and psychic symptom of dementia (BPSD). Data about rehabilitation of femur fracture in patients with BPSD are scanty. When BPSD is relevant, in Italy we deal them in a Special Care Unit (SCU), which includes an inpatient rehabilitative short-stay ward. The vision that informs our approach is the "GentleCare" prosthetic model of care [16].

\section{Paper's Purpose}

The aim of the present work was to gauge rehabilitative results in such specific context of problems and care. Our primary goal was to measure locomotor, functional and behavioral rehabilitative results in an SCU context. Secondary goals were to link those results with each other, and to pick out factors impinging on improvements in performance.

\section{Material and Methods}

The study is designed as retrospective evaluation of rehabilitative outcome of elderly demented persons with BPDS and hip fracture in a SCU. 


\subsection{Context}

Within the Italian Health Care System the rehabilitation context of care is graduated in terms of intensiveness of care. Special Care Units for Alzheimer's disease and related disorder pertain to an intermediate level of intensity of care and accept persons with dementia associated to BPSD who need a rehabilitative intervention [17] [18]. Information about a convenience sample of 54 patients discharged from Hospital and admitted between 2005 and 2010 for hip fracture were collected from the data base of the Golgi Institute Alzheimer's Special Care Unit. Due to the exploratory nature of our enquiry, neither sample size calculation nor selection criteria were applied. In this context, rehabilitation programs are delivered on the bases of the "Prosthetic Model of Care" Inspired to GentleCare ${ }^{\circledR}$ by Moyra and Marc Jones [16].

The prosthetic model for dementia identifies deficits in function in the patient and builds a "prosthesis of care" for each individual that is intended to compensate for the lost functions. The main goal of the prosthesis is not to merely regain cognition and function, but to deal with the well-being of the person, to achieve the best functional status in absence of distress and pain. For this purpose a complex prosthesis is needed, made up of 3 basic elements: the individuals with whom the person with dementia interacts, the physical space in which the person lives, and the programs and activities in which the person engages.

Staff, relatives, and anyone else in contact with an individual with dementia must understand the nature of the deficits caused by dementia.

In respect of the physical space, safety, comfort and access are the most important features. An environment with a rich infrastructure promotes interaction and reinforce the rehabilitation approach.

Programs must be individually tailored and modulated on the bases of a multidimensional evaluation aimed to balance patient's deficits and strengths.

Finally in GentleCare ${ }^{\circledR}$ model BPSD are considered as the expression of an imbalance between the abilities of the individual with dementia and environmental demands, and not just the expression of the pathology. The approach to BPSD is, in this respect, mainly interpretative. These features constitute GentleCare ${ }^{\circledR}$ approach’s strengths; its limitation consists in lack of a formal validation, yet being formally certified.

The multidimensional assessment consists of cognitive evaluation [Mini Mental State Examination: MMSE; Clinical Dementia Rating: CDR; GDS Global Deterioration Scale (global evaluation assessment tools)] [19]-[21], functional evaluation [Barthel Index (for 10 basic activities of daily life), Tinetti Gait and Balance (static and dynamic equilibrium), Bedford Alzheimer Nursing Severity scale: BANS-s (functional status assessment tool for severely disabled patients)] [21]-[24], behavioural evaluation (UCLA Neuropsychiatric Inventory: NPI) [25], comorbidity evaluation (Cumulative Illness Rating Scale: CIRS) (the latter tools being among the most widely used assessment tools) [26].

The rehabilitation program is carried out by a physiotherapist and an occupational therapist trained on dementia and BPSD.

A psychologist is also part of the team and helps in approaching and answering to the BPSD presented by the person with dementia.

We previously shown improvements in BPSD that followed plausible trajectories, by factor analysis [27].

Data used for analysis were collected as part of routine clinical practice: therefore following advice from the local ethics committee formal approval was not sought.

\subsection{Sample}

About demographic data, 48 of our 54 subjects were women (89\%), mean age was 82.3 years (s.d. 6.13 ; range 66 - 94). Their diagnosis were: Alzheimer's dementia 56\%, vascular dementia 28\%, other dementias $16 \%$. Dementia staging was: CDR median 3 (interquartile range $=3-3$ ) and GDS median 6 (interquartile range $=6$ - 7).

As for clinical assessment at entry mean CIRS Severity Index was 1.89 (s.d. 0.22) and mean CIRS Comorbidity Index was 4.27 (s.d. 1.45).

Hip fracture treatment was: hip replacement $39 \%$, osteosynthesis $56.1 \%$, no surgery $4.9 \%$.

Length of stay was 45.99 days (s.d. 48.95). Social outcome was discharge to home for 70.5\% of subjects.

\subsection{Statistical Analysis}

We use mean and standard deviation and percentage distribution for continuous and categorical variables re- 
spectively. Associations were measured using linear Pearson's correlation (or Spearman's rho for not normally distributed data). Descriptive and inferential analyses were performed by SPSS, release 11.0.

\section{Results}

Concerning our primary goal, as shown in Table 1, all measured locomotor, functional, behavioral variablesconstituting the multidimensional assessment [see Methods] —improved, with a trend for cognitive improvement. The size of improvements in locomotor, functional and behavioral performances were both statistically $(\mathrm{p}<0.01)$ and clinically significant. Clinical Dementia Rating (CDR) couldn’t improve, due to its intrinsic nature.

Focusing more specifically on behaviors, Table 2 shows the decline in prevalence of most relevant single BPSD between admission and discharge. More, the same table shows as each behavioral problem declines in frequency and severity throughout the rehabilitative stay in SCU.

As for secondary goals, we found many correlations (rho; p) between locomotor, functional and behavioral variables. Due to the features of respective parameters, negative correlations mean that locomotor and functional performances are better in the case of less disturbed behaviours, whilst positive correlations implicate better locomotor and functional performances in the face of more disturbed behaviors. At admission, Tinetti balance correlated negatively with agitation $(-0.417 ; 0.027)$ and disinhibition $(-0.410 ; 0.022)$, and positively with anxiety $(0.520 ; 0.003)$ and eating behaviour $(0.364 ; 0.044)$. At entry, Tinetti gait correlated negatively with agitation $(-0.564 ; 0.001)$ and disinhibition $(-0.503 ; 0.005)$. At admission, Barthel Index total score correlated positively with delusions $(0.332 ; 0.017)$ and negatively with disinhibition $(-0.319 ; 0.023)$. At discharge, either Tinetti balance $(-0.444 ; 0.003)$ or Tinetti gait $(-0.449 ; 0.003)$ correlated negatively with agitation, whilst Barthel Index total score correlated negatively with agitation $(-0.418 ; 0.004)$ and with apathy $(-0.321 ; 0.03)$.

No correlation was found between BPSD assessed at admission and gains neither in Tinetti test performances nor in Barthel Index total score. Improvements in Tinetti test total score correlated negatively with agitation measured at discharge $(-0.380 ; 0.042)$. Gains in Barthel Index total score correlated negatively with agitation $(-0.301 ; 0.042)$, apathy $(-0.489 ; 0.001)$ and eating behaviours $(-0.343 ; 0.02)$-assessed at discharge.

Comparing respective values between admission and discharge, neither modifications in Tinetti test performances nor in Barthel Index total score correlated with changes in BPSD.

In a multiple linear regression model $24 \%$ of improvement in Barthel Index total score was explained by agitation and apathy at discharge: better functional levels corresponded to smoother behavioural problems.

As most patients improved, we couldn't compare people with good versus poor outcome.

Table 1. Locomotor, functional, behavioral and cognitive variables at admission and at discharge.

\begin{tabular}{ccccccc}
\hline $\begin{array}{c}\text { Variables in row } \\
\text { (mean } \pm \text { s.d.) }\end{array}$ & Tinetti balance & Tinetti gait & $\begin{array}{c}\text { Barthel index } \\
\text { (total score) }\end{array}$ & BANSS & $\begin{array}{c}\text { NPI } \\
\text { (total score) }\end{array}$ & MMSE \\
\hline Admission & $2.5 \pm 2.3$ & $4 \pm 3.7$ & $10.1 \pm 11$ & $20.3 \pm 2.7$ & $38 \pm 12.6$ & $10.2 \pm 4.9$ \\
Discharge & $6 \pm 3.5$ & $6.5 \pm 3.3$ & $26.3 \pm 17.1$ & $18 \pm 3.2$ & $12.1 \pm 8.7$ & $12.4 \pm 4.5$ \\
$* \mathrm{p}<0.01$ & $*$ & $*$ & $*$ & $*$ & $*$ & n. s. \\
\hline
\end{tabular}

Table 2. Behavioral evaluation at admission and at discharge (UCLA Neuropsychiatric Inventory: NPI selected items).

\begin{tabular}{|c|c|c|c|c|c|c|}
\hline & Delusions & Hallucination & Agitation & Irritability & $\begin{array}{c}\text { Aberrant motor } \\
\text { activity }\end{array}$ & $\begin{array}{l}\text { Sleep and nighttime } \\
\text { behavior disorders }\end{array}$ \\
\hline Prevalence at admission (\%) & 42.3 & 36.5 & 53.8 & 44.2 & 61.5 & 55.8 \\
\hline Prevalence at discharge (\%) & 9.6 & 11.5 & 34.6 & 15.4 & 34.6 & 15.4 \\
\hline NPI admission (mean \pm s.d.) & $2.6 \pm 3.7$ & $2 \pm 3.1$ & $4.1 \pm 4.5$ & $3.3 \pm 4.4$ & $5.2 \pm 5$ & $5 \pm 5.1$ \\
\hline NPI discharge (mean \pm s.d.) & $0.3 \pm 1$ & $0.4 \pm 1.1$ & $1.8 \pm 3$ & $0.6 \pm 1.6$ & $1.9 \pm 3.4$ & $0.8 \pm 2.3$ \\
\hline${ }^{*} \mathrm{p}<0.01^{\S}$ & $*$ & $*$ & $*$ & $*$ & $*$ & * \\
\hline
\end{tabular}

${ }^{\#}$ Frequency $\times$ severity ratings; ${ }^{\S}$ Statistical significance $(\mathrm{p}<0.01)$ pertains both to prevalence and to frequency $\times$ severity ratings. 


\section{Discussion}

Our results show that improvement in both locomotor-functional and behavioral areas are achievable in patients with hip fracture and BPSD, fulfilling the primary goal of the study. We found also some plausible relationships between locomotor, functional and behavioral parameters, so that better locomotor and functional levels corresponded to lighter behavioral problems. This is especially true for BPSD at discharge. We guess that BPSD persistence might impact on functional performance. Our study has some limitations, either about methods or results. We acknowledge the small entity of our sample as well as of locomotor and functional results. More, we couldn't catch any direct correlation between improvements in locomotor or functional levels and reduction in BPSD, at variance with what we expected. This may be explained in different ways. The most basic explanation is that the BPSD has no significant relevance for the efficacy of the rehabilitation, but this is in contrast with the correlations of functional status and single BPSD both at admission and at discharge. An alternative explanation is that the BPSD acts primarily on the functional condition rather than on the functional gain; another more intriguing explanation is that the recovery process was performed in an environment specially crafted to manage BPSD so that the influence of this aspect on the functional results is reduced.

Hip fractures are a leading cause of disability and mortality in the elderly, resulting in significant functional impairment and excessive institutionalization. Further, cognitive deterioration is linked to perceptual and neuromotor disorders [28]-[36]. More, cognitive deterioration leads to proneness towards behavior disorders-in case of gap between the abilities of the individual with dementia and environmental demands [16]. Our data shows generalized functional gains, but although significant, they are somewhat less than improvement reported in not demented subjects. We must interpret these data cautiously, taking into account pre-fracture physical and mental levels [37]. We underscore the low baseline levels of locomotor and functional abilities in face of the high levels of problem behaviors, in our sample of persons with dementia. Hence we can explain the lesser functional gain - either absolute or relative - in our demented SCU patients, when compared to hip fractured elderly without relevant BPSD, cared in a usual geriatric rehabilitative ward. In the latter context, our standard achieves a mean increase of 27 (e.g. $42 \rightarrow$ 69) points in Barthel Index total score [own data], corresponding to a relative gain of $45.6 \%$, according to the Montebello Rehabilitation Factor Score [13]. In the current SCU context, we got an absolute mean gain of 16 points in Barthel Index total score, corresponding to a relative improvement of $17 \%$. Failure to consider functional status prior to fracture might overestimate the impact of cognitive status on functional outcome of hip fractured patients [38]. In a Finnish sample, patients with low $(\leq 11 / 30)$ MMSE scores before hip fracture had a significantly greater degree of basic ADL dependence than the other three groups (MMSE $=12-17 / 30,18-23 / 30$ and $\geq 24 / 30$ ). Despite similar post-operative multidisciplinary treatment, functional ability remained at the lower level in the two lower MMSE groups, whereas recovery was much better in the two higher MMSE groups [39]. Admission cognitive function (MMSE) and pre-injury functional level were among the most important prognostic factors associated with rehabilitation success in another sample of older patients with proximal hip fracture [40]. Functional improvement similar to patients with good cognition has been achieved in an Italian experience also by people with MMSE $<18 / 30$, provided they are in good nutritional status [41]. We previously shown a distribution in serum albumin level as a function of dependence groups (p 0.0001 by analysis of variance), so that higher protein concentrations were found in less dependent SCU patients, stratified into Barthel Index total score classes [42].

The role of cognitive deterioration and related problems on the outcomes of rehabilitation after hip fracture are still a matter of debate. Pre-fracture motor and not cognitive level has been the most important predictive factor for motor gain after hip fracture. Cognitively impaired hip fracture patients can achieve and maintain the same motor functional gain as normal patients, if they were mobile pre-fracture [43]. Although less frequently than in individuals with better cognitive function, walking independence is achievable after hip fracture surgery rehabilitation, and can be maintained at 1 year also in those with moderately severe or severe cognitive impairment [44].

According to a recent review, people with mild or moderate dementia may show improved function and ambulation and decreased fall risk after rehabilitation post hip fracture, similar to gains achieved by those without dementia. More research is required to ascertain the effect of rehabilitation in people with moderate to severe dementia, including those residing in continuing-care settings [45]. We shown elsewhere that that poor cognitive status bears heavily on frailty, but it does not hamper the outcomes of rehabilitation in geriatric patients, with disability following fractures, hemiplegia, joint replacement, but also immobilization syndromes due to parkin- 
sonism, heart failure, vascular peripheral diseases, or convalescence after medical or surgical hospital stays, and related complications such as pressure sores or dysphagia [46].

The role of a suitable rehabilitative context - with special regard towards SCU—can be drawn by the confrontation of rehabilitation outcome achieved in inpatient rehabilitation facility as compared to skilled nursing facility. Post-fracture patients with depression, apathy or cognitive impairment who received rehabilitation at an inpatient rehabilitation facility had significantly better functional outcomes than similarly-impaired patients at skilled nursing facility, and similar outcomes as non-depressed, motivated, and cognitively intact elderly at inpatient rehabilitation facility [47]-[50].

\section{Conclusion}

In conclusion, our results—-notwithstanding their clear limitations—support the practice of caring for hip fractured patients with BPSD in a SCU, wherein several different clinical, functional and behavioral problems can be properly addressed. All the aspects of the inpatients significantly improved at the discharge, in a size that can really relieve the dependency in the everyday life of the persons with dementia and with the aftereffects of the hip fracture. For these individuals the presence of the associated behavioral disturbances has a limited weight for the rehabilitation outcome and it does not hinder an intensive multidimensional rehabilitative intervention in an appropriate environment.

\section{References}

[1] Salkeld, G., Cameron, I.D., Cumming, R.G., Easter, S., Seymour, J., Kurlle, S.E., et al. (2000) Quality of Life Related to Fear of Falling and Hip Fracture in Older Women: A Time Trade off Study. British Medical Journal, 320, 341-345. http://dx.doi.org/10.1136/bmj.320.7231.341

[2] Young, Y., Brant, L., German, P., Kenzora, J. and Magaziner, J. (1997) Longitudinal Examination of Functional Recovery among Older People with Subcapital Hip Fractures. Journal of the American Geriatrics Society, 45, $288-294$. http://dx.doi.org/10.1111/j.1532-5415.1997.tb00942.x

[3] Magaziner, J., Hawkes, W., Hebel, J.R., Zimmerman, S.I., Fox, K.M., Dolan, M., et al. (2000) Recovery from Hip Fracture in Eight Areas of Function. Journal of Gerontology A Biological Sciences Medical Sciences, 55, M498-M507. http://dx.doi.org/10.1093/gerona/55.9.m498

[4] Piscitelli, P., Iolascon, G., Argentiero A., Chitano, G., Neglia, C., Marcucci, G., et al. (2012) Incidence and Costs of Hip Fractures vs Strokes and Acute Myocardial Infarction in Italy: Comparative Analysis Based on National Hospitalization Records. Clinical Interventions in Aging, 7, 575-583. http://dx.doi.org/10.2147/CIA.S36828

[5] Schuman, J.E., Beattie, E.J., Steed, D.A., Merry, G.M. and Kraus, A.S. (1981) Geriatric Patients with and without Intellectual Dysfunctions: Effectiveness of a Standard Rehabilitation Program. Archives of Physical Medicine and Rehabilitation, 62, 612-618.

[6] Baker, B.R., Duckworth, T. and Wilkes, E. (1978) Mental State and Other Prognostic Factors in Femoral Fractures in the Elderly. The Journal of the Royal College of General Practitioners, 28, 557-559.

[7] Billig, N., Ahmed, S.W. and Kenmore, P.I. (1988) Approaches to Senior Care \# 1. Hip Fracture, Depression, and Cognitive Impairment: A Follow-Up Study. Orthopaedic Review, 17, 315-320.

[8] Hershkovitz, A., Jacubovski, O.S., Alima Bot, M., Oshry, V. and Brill, S. (2010) Clock Drawing and Rehabilitation Outcome in Hip Fracture Patients. Disability and Rehabilitation, 32, 2013-2017. http://dx.doi.org/10.3109/09638288.2010.482175

[9] Reuling, E.M.B.P., Sierevelt, I.N., van dem Bekerom M.P.J., Hilverdink, E.F., Schnater, J.N., van Dijk, C.N., et al. (2012) Predictors of Functional Outcome Following Femoral Neck Fractures Treated with an Arthroplasty: Limitations of the Harris Hip Score. Archives of Orthopaedic and Trauma Surgery, 132, 249-256. http://dx.doi.org/10.1007/s00402-011-1424-0

[10] Jette, A.M., Harris, B.A., Cleary, P.D. and Campion, E.W. (1987) Functional Recovery after Hip Fractures. Archives of Physical Medicine and Rehabilitation, 68, 735-740.

[11] Barnes, B. (1984) Ambulation Outcomes after Hip Fractures. Physical Therapy, 64, 317-320.

[12] Goldstein, F.C., Strasser, D.C., Woodaed, J.L. and Roberts, V.J. (1997) Functional Outcome of Cognitively Impaired Hip Fracture Patients on a Geriatric Rehabilitation Unit. Journal of the American Geriatrics Society, 45, 35-42. http://dx.doi.org/10.1111/j.1532-5415.1997.tb00975.x

[13] Heruti, R.J., Lusky, A., Barell, V., Ohry, A. and Adunsky, A. (1999) Cognitive Status at Admission: Does It Affect the Rehabilitation Outcome of Elderly Patients with Hip Fracture? Archives of Physical Medicine and Rehabilitation, 80, 
432-436. http://dx.doi.org/10.1016/S0003-9993(99)90281-2

[14] Huusko, T.M., Karppi, P., Avikainen, V., Kautiainen, H. and Sulkava, R. (2000) Randomised, Clinically Controlled Trial of Intensive Geriatric Rehabilitation in Patients with Hip Fracture: Subgroup of Patients with Dementia. British Medical Journal, 321, 1107-1111. http://dx.doi.org/10.1136/bmj.321.7269.1107

[15] Bellelli, G., Frisoni, G.B., Pagani, M., Magnifico, F. and Trabucchi, M. (2007) Does Cognitive Performance Affect Physical Therapy Regimen after Hip Fracture Surgery? Aging Clinical and Experimental Research, 19, 119-124. http://dx.doi.org/10.1007/BF03324677

[16] Guaita, A. and Jones, M. (2011) A Prosthetic Approach for Individuals with Dementia? JAMA: The Journal of the American Medical Association, 305, 402-403. http://dx.doi.org/10.1001/jama.2011.28

[17] Bellelli, G., Frisoni, G.B., Bianchetti, A., Boffelli, S., Guerrini, G.B., Scotuzzi, A., et al. (1998) Special Care Units for Demented Patients: A Multicenter Study. The Gerontologist, 38, 456-462. http://dx.doi.org/10.1093/geront/38.4.456

[18] Nobili, A., Piana, I., Balossi, L., Pasina, L., Matucci, M., Tarantola, M., Trevisan, S., et al. (2008) Alzheimer Special Care Units Compared with Traditional Nursing Home for Dementia Care: Are There Differences at Admission and in Clinical Outcomes? Alzheimer Disease and Associated Disorders, 22, 352-361. http://dx.doi.org/10.1097/WAD.0b013e31818207d0

[19] Folstein, M.F., Folstein, S.E. and McHugh, P.R. (1975) Mini-Mental State: A Practical Method for Grading the Cognitive State of Patients for the Clinician. Journal of Psychiatric Research, 12, 189-198. http://dx.doi.org/10.1016/0022-3956(75)90026-6

[20] Morris, J.C. (1993) The Clinical Dementia Rating (CDR): Current Version and Scoring Rules. Neurology, 43, 24122414. http://dx.doi.org/10.1212/WNL.43.11.2412-a

[21] Reisberg, B., Ferris, S.H., De Leon, M.J. and Crook, T. (1982) The Global Deterioration Scale for Assessment of Primary Degenerative Dementia. The American Journal of Psychiatry, 139, 1136-1139. http://dx.doi.org/10.1176/ajp.139.9.1136

[22] Shah, S., Vanclay, F. and Cooper, B. (1989) Improving the Sensitivity of the Barthel Index for Stroke Rehabilitation. Journal of Clinical Epidemiology, 42, 703-709. http://dx.doi.org/10.1016/0895-4356(89)90065-6

[23] Tinetti, M.E. (1986) Performance-Oriented Assessment of Mobility Problems in Elderly Patients. Journal of the American Geriatrics Society, 34, 119-126. http://dx.doi.org/10.1111/j.1532-5415.1986.tb05480.x

[24] Bellelli, G., Frisoni, G.B., Bianchetti, A. and Trabucchi, M. (1997) The Bedford Alzheimer Nursing Severity Scale for the Severely Demented: Validation Study. Alzheimer Disease and Associated Disorders, 11, 71-77. http://dx.doi.org/10.1097/00002093-199706000-00003

[25] Cummings, J.L., Mega, M., Gray, K., Rosenberg-Thompson, S., Carusi, D.A. and Gornbein, J. (1994) The Neuropsychiatric Inventory: Comprehensive Assessment of Psychopathology in Dementia. Neurology, 44, 2308-2314. http://dx.doi.org/10.1212/WNL.44.12.2308

[26] Parmalee, P.A., Thuras, P.D., Katz, I.R. and Lawton, M.P. (1995) Validation of the Cumulative Illness Rating Scale in a Geriatric Residential Population. Journal of the American Geriatrics Society, 43, 130-137. http://dx.doi.org/10.1111/j.1532-5415.1995.tb06377.x

[27] Colombo, M., Vitali, S., Cairati M., Vaccaro, R., Andreoni, G. and Guaita, A. (2007) Behavioural and Psychotic Symptoms of Dementia Improvements in a Special Care Unit: A Factor Analysis. Archives of Gerontology and Geriatrics, 44, 113-120. http://dx.doi.org/10.1016/j.archger.2007.01.017

[28] Rizzo, M. and Nawrot, M. (1998) Perception of Movement and Shape in Alzheimer’s Disease. Brain, 121, $2259-2270$. http://dx.doi.org/10.1093/brain/121.12.2259

[29] Kavcic, V. and Duffy, C.J. (2003) Attentional Dynamics and Visual Perception: Mechanisms of Spatial Disorientation in Alzheimer's Disease. Brain, 126, 1173-1181. http://dx.doi.org/10.1093/brain/awg105

[30] Baddeley, A.D., Baddeley, H.A., Bucks, R.S. and Wilcock, G.K. (2001) Attentional Control in Alheimer’s Disease. Brain, 124, 1492-1508. http://dx.doi.org/10.1093/brain/124.8.1492

[31] Sheridan, P.L., Solomont, J., Kowall, N. and Hausdorff, J.M. (2003) Influence of Executive Function on Locomotor Function: Divided Attention Increases Gait Variability in Alzheimer's Disease. Journal of the American Geriatrics Society, 51, 1633-1637. http://dx.doi.org/10.1046/j.1532-5415.2003.51516.x

[32] Kluger, A., Gianutsos, J.G., Golomb, J., Ferris, S.H., George, A.E., Franssen, E., et al. (1997) Patterns of Motor Impairment in Normal Aging, Mild Cognitive Decline, and Early Alzheimer's Disease. Journal of Gerontology B Psychological Sciences Social Sciences, 52, P28-P39. http://dx.doi.org/10.1093/geronb/52B.1.P28

[33] Montero-Odasso, M., Muir, S.W. and Speechley, M. (2012) Dual-Task Complexity Affects Gait in People with Mild Cognitive Impairment: The Interplay between Gait Variability, Dual Tasking, and Risk of Falls. Archives of Physical Medicine and Rehabilitation, 93, 293-299. http://dx.doi.org/10.1016/j.apmr.2011.08.026 
[34] Kearns, W.D. (2010) Elder Path Tortuosity Covaries with MMSE Geographical Orientation Subscale. Gerontechnology, 9, 176-177. http://dx.doi.org/10.4017/gt.2010.09.02.020.00

[35] Kearns, W.D. (2010) Of Falls and Fractals: My Career with My Mentor, Colleague and Friend, Professor James L. Fozard. Gerontechnology, 9, 388-396. http://dx.doi.org/10.4017/gt.2010.09.03.010.00

[36] Orcioli-Silva, D., Simieli, L., Barbieri, F.A., Stella, F. and Gobbi, L.T. (2012) Adaptive Walking in Alzheimer’s Disease. International Journal of Alzheimer's Disease, 2012, Article ID: 674589.

[37] Marottoli, R.A., Berkman, L.F. and Cooney, L.M. (1992) Decline in Physical Function Following Hip Fracture. Journal of the American Geriatrics Society, 40, 861-866. http://dx.doi.org/10.1111/j.1532-5415.1992.tb01980.x

[38] Dubljanin-Raspopović, E., Marković-Denić, L., Matanović, D., Grajić, M., Krstić, N. and Bumbaširević, M. (2012) Is Pre-Fracture Functional Status Better than Cognitive Level in Predicting Short-Term Outcome of Elderly Hip Fracture Patients? Archives of Medical Sciences, 8, 115-122. http://dx.doi.org/10.5114/aoms.2012.27291

[39] Häkkinen, A., Heinonen, M., Kautiainen, H., Huusko, T., Sulkava, R. and Karppi, P. (2007) Effect of Cognitive Impairment on Basic Activities of Daily Living in Hip Fracture Patients: A 1-Year Follow-Up. Aging Clinical and Experimental Research, 19, 139-144. http://dx.doi.org/10.1007/BF03324680

[40] Hershkovitz, A., Kalandariov, Z., Hermush, V., Weiss, R. and Brill, S. (2007) Factors Affecting Short-Term Rehabilitation Outcomes of Disabled Elderly Patients with Proximal Hip Fracture. Archives of Physical Medicine and Rehabilitation, 88, 916-921. http://dx.doi.org/10.1016/j.apmr.2007.03.029

[41] Ghisla, M.K., Cossi, S., Timpini, A., Baroni, F., Facchi, E. and Marengoni, A. (2007) Predictors of Successful Rehabilitation in Geriatric Patients: Subgroup Analysis of Patients with Cognitive Impairment. Aging Clinical and Experimental Research, 19, 417-423. http://dx.doi.org/10.1007/BF03324724

[42] Colombo, M. and Vitali, S. (1998) Nutritional Problems in Demented Elderly. Studies in Health Technology and Informatics, 48, 266-268.

[43] Beloosesky, Y., Grinblat, J., Epelboym, B., Weiss, A., Grosman, B. and Hendel, D. (2002) Functional Gain of Hip Fracture Patients in Different Cognitive and Functional Groups. Clinical Rehabilitation, 16, 321-328. http://dx.doi.org/10.1191/0269215502cr497oa

[44] Morghen, S., Gentile, S., Ricci, E., Guerini, F., Bellelli, G. and Trabucchi, M. (2011) Rehabilitation of Older Adults with Hip Fracture: Cognitive Function and Walking Abilities. Journal of the American Geriatrics Society, 59, 14971502. http://dx.doi.org/10.1111/j.1532-5415.2011.03496.x

[45] Allen, J., Koziak, A., Buddingh, S., Liang, J., Buckingham, J. and Beaupre, L.A. (2012) Rehabilitation in Patients with Dementia Following Hip Fracture: A Systematic Review. Physiotherapy Canada, 64, 192-201. http://dx.doi.org/10.3138/ptc.2011-06BH

[46] Colombo, M., Guaita, A., Cottino, M., Previderè, G., Ferrari, D. and Vitali, S. (1994) The Impact of Cognitive Impairment on the Rehabilitation Process in Geriatrics. Archives of Gerontology and Geriatrics. Supplement, 9, 85-92.

[47] Lenze, E.J., Skidmore, E.R., Dew, M.A., Butters, M.A., Rogers, J.C., Begley, A., et al. (2007) Does Depression, Apathy or Cognitive Impairment Reduce the Benefit of Inpatient Rehabilitation Facilities for Elderly Hip Fracture Patients? General Hospital Psychiatry, 29, 141-146. http://dx.doi.org/10.1016/j.genhosppsych.2007.01.001

[48] Eriksson, S., Gustafson, Y. and Lundin-Olsson, L. (2007) Characteristics Associated with Falls in Patients with Dementia in a Psychogeriatric Ward. Aging Clinical and Experimental Research, 19, 97-103. http://dx.doi.org/10.1007/BF03324674

[49] Taniguchi, S., Narumoto, J., Shibata, K., Ayani, N., Matsuoka, T., Okamura, A., et al. (2013) Treatment in a Ward for Elderly Patients with Dementia in Japan. Neuropsychiatric Disease and Treatment, 9, 357-363. http://dx.doi.org/10.2147/NDT.S41581

[50] Sylliaas, H., Selbæk, G. and Bergland, A. (2012) Do Behavioral Disturbances Predict Falls among Nursing Home Residents? Aging Clinical and Experimental Research, 24, 251-256. http://dx.doi.org/10.1007/BF03325253 